Zhang, S., Derudder, B. \& Witlox, F. (2016). Dynamics in the European Air Transport Network, 2003-9: An Explanatory Framework Drawing on Stochastic Actor-Based Modeling. Networks and Spatial Economics, accepted for publication.

\title{
Dynamics in the European Air Transport Network, 2003-9: An Explanatory Framework Drawing on Stochastic Actor-Based Modeling
}

\begin{abstract}
In this paper, we outline and test an explanatory framework drawing on stochastic actor-based modeling to understand changes in the outline of European air transport networks between 2003 and 2009. Stochastic actor-based models show their capabilities to estimate and test the effect of exogenous and endogenous drivers on network changes in this application to the air transport network. Our results reveal that endogenous structural effects, such as transitivity triads, indirect relations and betweenness effects impact the development of the European air transport network in the period under investigation. In addition, exogenous nodal and dyadic covariates also play a role, with above all the enlargement of the European Common Aviation Area having benefitted its new members to open more air routes between them. The emergence of major low-cost airline-focused airports also significantly contributed to these changes. We conclude by outlining some avenues for further research.
\end{abstract}

Keywords Airport network dynamics $\cdot$ Europe $\cdot$ Stochastic-actor based models $\cdot$ Deregulation

\section{Introduction}

The deregulation of the air transport industry in Europe through the implementation of three subsequent deregulation 'packages' has greatly affected and transformed the entire sector. As a consequence, over the last decades air transport networks in Europe have undergone major changes in terms of structure, capacity, demand and scale.

The structure of European airport network has evolved into a complex, multi-layered network consisting of hub-and-spoke and point-to-point networks (Malighetti et al., 2009). This mixed structure consists of a number of overlapping networks, but also and perhaps above all of a number of parallel networks (De Neufville, 2004). Ryanair, for instance, which is known to operate a point-to-point network, offers service between London, Brussels and Frankfurt via London/Stansted, Brussels/Charleroi, and Frankfurt/Hahn rather than through London/Heathrow, Brussels/Zaventem and Frankfurt/Main. In addition, air transport services tend to shift towards second ranked cities due to changes in global production and the use of smaller long-haul aircraft (O'Connor and Fuellhart, 2013; O'Connor, 2003). The deconcentration of air transport networks may imply opportunities for secondary airports, and pose challenges for large hub airports. 
Changing structures have coincided with network expansion. Burghouwt and Hakfoort (2001) found that the total seat capacity of European airport network has grown by 59\% between 1990 and 1998, while the growth of intercontinental traffic and intra-European traffic has surpassed 70\%. Fan (2006), examining intra-European flights between 1996 and 2004 found that the number of cities served increased by $40 \%$ (from 94 to 135), while the number of city-pairs surged by $91 \%$ (from 224 to 428). Air travel in Europe continues to grow at a rapid rate, as Eurocontrol forecasts there will be 14.4 million yearly flights in Europe by 2035, which would be $50 \%$ more than in 2012 at a growth rate of $1.8 \%$ per year (EUROCONTROL, 2013).

These overall figures clearly indicate that the European airport network continues to experience both growth and change. However, to date relatively little attention has been paid to the factors driving the changes in European air transport networks. Exceptions are the studies by Burghouwt and Hakfoort (2001) and Fan (2006). In Burghouwt and Hakfoort (2001), the authors investigate how the capacity of the European airport network changed over the period 1990-1998 at the airport and the route level. Although their distinction between airport and route level change overcomes the drawbacks of previous empirical studies in that the nature of change is better revealed, the study remains descriptive, thus largely ignoring the interdependence between airport (nodal) and route (dyadic) attributes. Fan (2006) provides more evidence on the evolution of inter-city air transport connectivity in Europe, showing for instance that network growth is mostly attributable to the rising importance of low-cost carriers. His analysis, however, does not explore other factors that may be driving the evolution of air transport networks in Europe.

Taken together, it is clear that our understanding of the spatial-temporal development of European air transport networks can be enhanced by addressing the mechanisms of change and growth in a more comprehensive way. The objective of this paper is to explore and interpret the factors driving changes in European airport networks. To this end, we apply a stochastic actorbased modeling (SABM) framework. To our knowledge, this is the first time that SABM is applied in a longitudinal analysis of air transport networks. Reviewing recent theoretical and empirical research suggests that SABM has indeed the potential to shed light on the processes underlying network dynamics (Andrew, 2009; Buchmann and Pyka, 2013; Ingold and Fischer, 2014; KINNE, 2013; Liu et al., 2013c). The main advantages of applying SABM to examine network dynamics are that (1) the modeling framework encompasses a wide variety of endogenous and exogenous effects on network change, and (2) allows evaluating these effects in the spirit of statistical inference (i.e. by providing parameter estimates that allow for the formal testing of hypotheses regarding potential drivers of network change).

The remainder of this paper is structured as follows. In the next section (2), we discuss the conceptual parallels between the analysis of air transport structures and (social) network analysis in which SABM was developed. This is essential as one of the basic assumptions of SABM is that actors control and change their outgoing ties based on their and others' attributes, their roles in the network and their interactions throughout the rest of the network (Snijders et al., 2010): unless it can be established that this assumption holds in the case of air transport networks, 
applying SABM would be a mere statistical exercise without much formative remit. The following sections outline the collection of longitudinal network data (3) and the methodological core of SABM (4). We then specify the SABM framework applied in this research by introducing the endogenous network and the exogenous actor and dyadic attributes used in the modeling (5), after which we discuss the main results of our analysis (6). In the final section (7), we present our main conclusions and outline some avenues for further research.

\section{Air transport networks as 'social networks'?}

\subsection{Airports as 'actors' in air transport networks}

SABM has been developed in the domain of social network analysis, where 'networks' most commonly consist of interacting individuals who have the ability to exercise influence or (some degree of) control over their interactions. For SABM to be meaningful in other contexts, a discussion of how nodes or actors are able to exercise such influence is needed. In the present context, this entails a discussion of how airports can be considered as 'actors' in the development of airport transport networks. Of central importance in this discussion is the observation that the roles played by airports in the air transport value chain has changed over the last decades, as evidenced by their shifting operational objectives and their changing relationships with carriers, passengers and other airports.

Since the mid-1980, there has been a gradual shift in the ownership structures and operational objectives of airports. In (admittedly overly) general terms, before the mid-1980s airports tended to be government-owned, and primarily (or merely) seen as "logistic medium" to serve regional and/or macroeconomic development. From the mid-1980s on, however, the neoliberal 'logic' of privatization and commercialization has forced airports to function as "multipoint serviceprovider firms" 1 (Jarach, 2001) which focus on maximizing profitability by improving productive efficiency and competitiveness (Oum et al., 2006). Although this shift has been varied in its concrete operationalization, and has unfolded very unevenly in space and time, it seems fair to state that this is an overarching shift that has led airports to get more proactively involved as an actor in the air transport business by seeking interactions with the other key participants or 'actors' in air transport networks: carriers, passengers and other airports.

\subsection{Airport - carrier relationship}

Traditionally, airports and carriers worked together in a more or less stable supplier-customer relationship, whereby airports strived to attract a large number of carriers and provide them with infrastructure-related public services (e.g., air traffic control, ground-handling and other aviationrelated activities). However, deregulation and liberalization have altered this. The most conspicuous examples of this changing relationship can, of course, be found in the advent and

\footnotetext{
${ }^{1}$ Under this concept, an airport becomes a commercial hub, in which a bundle of diversified service propositions and products are offered to an enlarged category of target customers.
} 
proliferation of low-cost carriers (LCCs) and the increased competitive pressures on legacy or full-service carriers (FSCs). With FSCs increasingly being vulnerable to potential bankruptcy, for instance, there was the danger of spillover effects in that this could also bring down their hub airports. For instance, the bankruptcies of Aloha Airlines, Skybus Airlines, and ATA Airlines in 2008 cost Oakland International Airport over $\$ 2$ million in annual revenue due to losses in gate leases and landing fees (Waite, 2009). Meanwhile, LCCs have stimulated rapid growth at smaller airports. For example, the traffic at London Stansted languished at around 5 million per year in its first decade (De Neufville, 2004), but it became the fastest growing major international airport in the world and saw a substantial passenger growth of 25.6\% in 2000 (Francis et al., 2004) after being selected as a major base for Ryanair's operations. These dramatic changes have forced all airports to reexamine their relationship with carriers, with the former proactively and defensively participating in air transport business (Albers et al., 2005). Redondi et al. (2011), for instance, recently suggested that airports increasingly recommend new routes to carriers to improve their own network connectivity.

In addition to the (shifting) operational relationships between airports and carriers, their interaction is also shaped by the wider socio-economic context and unfolding liberalization of the airline market. First, even though it is airlines that realize the opening or closure of routes, their decisions regarding the anticipated profitability are influenced by the socio-economic context (e.g., the economic power measured by GDP, population and other indicators) of the cities or catchment areas in which airports are located. And second, only in relatively liberalized markets carriers can freely choose to open or close a route: when shaping (de)regulation policies, government and airport operators consider the overall geographies of air transport aggregated by airports (Van De Vijver et al., 2014), and these geographies are not solely or always directly shaped by individual carriers. From this perspective, airports implicitly co-determine the opening or closure of routes.

\subsection{Airport - passenger relationship}

Paralleling the changing ownership structure of airports and their shifting relations with carriers, airports also seek to transform their associations with passengers from an indirect airport - airline - passenger relationship to a more direct airport - passenger relationship (Francis et al., 2004). The most straightforward example is that some airports now try to sell tickets to passengers themselves, thus confronting airlines, tour operators and travel agents who historically controlled this business (Jarach, 2001). A very visible example of the changed role of airports in their relation with passengers has been Stansted's "Create your own connection" project, which helps passengers to 'self-hub' by taking advantage of its enormous potential for indirect connections (Malighetti et al., 2008). As independent, profit-seeking players in the air transport market they also tend place more and more emphasis on passenger revenues that are not strictly air transportrelated, such as spending in the terminals and car parks.

\subsection{Airport - airport relationship}


The relation between airports has transformed from being relatively independent entities into a closer relationship with cooperation and competition coexisting. On the one hand, cooperation can be expressed as opening a route between two airports to increase each other's accessibility. Connection modes (i.e., direct or indirect) can be varied between different levels of airports (i.e., 'hierarchy' of airports) emerging from (regional) economic development and individual airline network strategies (Burghouwt, 2007; Zhang et al., 2013). For instance, large hub airports tend to attract more direct connections than non-hub airports by reducing waiting time, routing and other related factors (Burghouwt and de Wit, 2005), while small airports in Europe strive to connect to a hub airport to indirectly reach more destinations or attract LCC services to have direct connections (Pels, 2008). On the other hand, and contrary to the conventional view that airports were monopoly providers of services to both airlines and passengers, airport markets in Europe are increasingly competitive in nature. In particular, they are likely to compete to each other in terms of local markets, connecting traffic, destinations and even cargo traffic (Tretheway and Kincaid, 2010). In particular, it is worth noting that secondary airports in Europe have shown to be intense competition for the major airports (Forsyth, 2010).

This overview suggests that airports are no longer the passive bystanders they used to be: they are increasingly becoming major actors in the air transport networks. Indeed, the underlying logic of profit-maximization and revenue-generation leads them to actively alter and manipulate their relations with other major actors in the airline business (carriers, passengers, and each other). Although clear not exactly the same as individuals managing their position in interpersonal (social) networks, we believe the resemblance is strong enough to explore the potential of methods devised in the context of social network analysis to explore the networks connecting airports. In particular, we focus on the application of a modeling framework that allows understanding how networks change over time: SABM.

\section{Data collection}

In this section, we introduce the data collection based on the requirements of SABM in terms of the number of observation moments, the number of actors, and the total number of changes between consecutive observations.

We examine changes in the European air transport network between 2003 and 2009. This sevenyear timespan guarantees the assumption of SABM that the total number of changes between two observations should not be too high or too low, as shown in table 1 and discussed below. If the total number of changes between consecutive observations is too high, this may violate the assumption that the network changes gradually. If, in turn, the total number of changes is too 
small, then SABM cannot provide enough information for estimating the parameters (Snijders et al., 2010) $)^{2}$.

In terms of collection of actor (airport) information, we first confine the geographical scope of our research as countries that signed European Common Aviation Area (ECAA) agreements before 2009. This includes all 27 EU members, alongside Norway, Iceland, Switzerland, Albania, Bosnia and Herzegovina, Croatia, Kosovo, Macedonia, Moldova, Montenegro and Serbia. In this ECAA, we selected the 120 airports serving more than 150,000 passengers in 2009 (i.e., the total number of the local origin, destination and transit passengers) ${ }^{3}$. Figure 1 shows the location of airports used in this study. Unsurprisingly, countries with a higher gross domestic product (GDP), a larger population, and a wider geographical extent tend to have more airports in the framework.

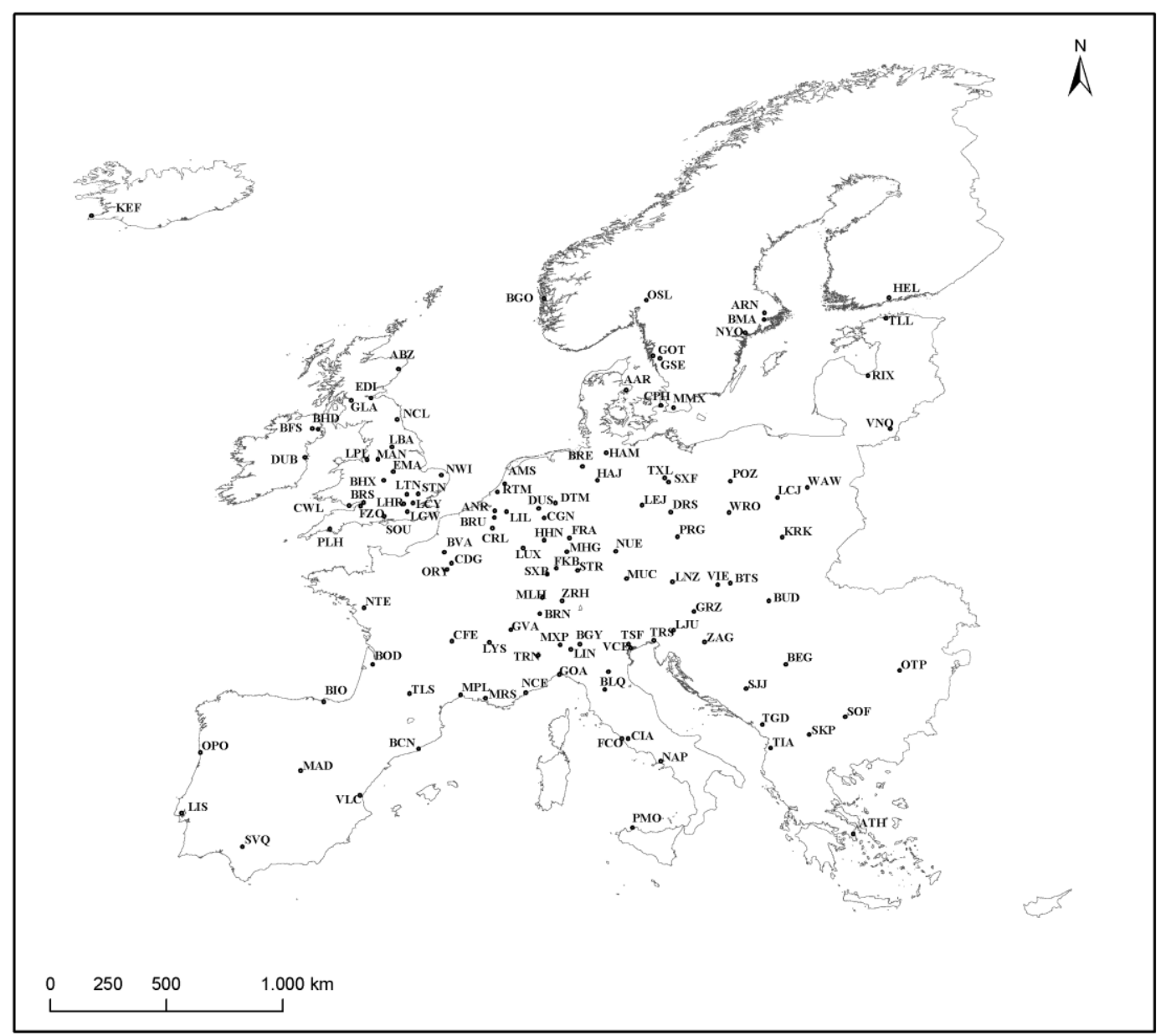

\footnotetext{
${ }^{2}$ Even though the air transport industry experienced the single largest $21^{\text {st }}$ century decline between our the two observation points of 2003 and 2009 due to the SARS epidemic and economic downturn (MacDonald, 2011), SABM seems capable of capturing the network change mechanisms between the two observations.

${ }^{3}$ This paper only considers airports where their located cities have a high global network connectivity (GNC) index (Neal, 2012). Some tourist destinations in Italy or Spain may, therefore, not be included in the analysis.
} 
Fig. 1 Location of airports in Europe

Drawing on this airport list, we constructed the network data that serves as the dependent variable in the model: two binary adjacency matrices representing the presence or absence of direct connections between airport pairs. The European air transport network in this analysis is a binary, non-directed and one-mode network. To achieve this, we collected data at the route level from Sabre Airline Solutions' Airport Data Intelligence (ADI), which contains information on actual connection between two airports (i.e., an airport pair directly connected by a commercial carrier). In order to obtain meaningful entries, we deleted routes with less than 100 passengers per year.

To obtain meaningful estimation results, SABM also provide quantitative indicators to measure the total number of tie changes between two consecutive observations. The Jaccard index is used to guarantee the gradual change of the networks, which is calculated as $N_{11} /\left(N_{11}+N_{01}+N_{10}\right)$, where $N_{11}, N_{01}$ and $N_{10}$ are the number of maintained ties, new ties and broken ties. Drawing on experience with the SABMs, the value of the Jaccard index should preferably be above 0.3 (Snijders et al., 2010). Table 1 shows that our data results in a Jaccard index of 0.573 , which implies that the underlying network-formation process can be modeled through SABM. Over the period from 2003 to 2009, the majority of the possible routes start by being absent and ended up so $(0 \rightarrow 0)$. About 18 percent significant connections remained unchanged, while 9 percent and 4 percent of routes were opened or canceled, respectively. The density of the network increased slightly and the average degree likewise also saw growth during the study period.

Table 1 Descriptive network statistics and tie changes between the two periods

\begin{tabular}{lll}
\hline Statistic & $\mathbf{2 0 0 3}$ & $\mathbf{2 0 0 9}$ \\
\hline Nodes & 120 & 120 \\
Density & 0.216 & 0.268 \\
Average degree & 25.717 & 31.917 \\
Existing ties & 1543 & 1915
\end{tabular}
Changes
$2003 \rightarrow 2009$

Jaccard index

0.573 


\begin{tabular}{ll}
\hline No tie: $\mathbf{0} \rightarrow \mathbf{0}$ & $4941(69 \%)$ \\
New tie: $\mathbf{0} \rightarrow \mathbf{1}$ & $656(9 \%)$ \\
Broken tie: $\mathbf{1} \rightarrow \mathbf{0}$ & $284(4 \%)$ \\
Maintained tie: $\mathbf{1} \rightarrow \mathbf{1}$ & $1259(18 \%)$ \\
\hline
\end{tabular}

\section{Stochastic actor-based models}

This paper employs stochastic actor-based models (SABMs) to examine the drivers of the air transport network change summarized in the previous section. Since their introduction for network dynamics by Snijders (1995) and his colleagues, SABMs have been widely applied in various fields, ranging from friendship networks (Cheadle et al., 2013) to inter-organizational networks (Liu et al., 2013a; Liu et al., 2013c; Van de Bunt and Groenewegen, 2007), manufacturing networks (Buchmann and Pyka, 2013), political networks (Andrew, 2009; KINNE, 2013), and many other areas. However, to date this approach has not been applied to air transport networks, probably in part because of the high requirements in terms availability of longitudinal network data, which has been a longstanding limitation to analyze the changes of transportation networks using statistical analysis tools (Xie and Levinson, 2009).

In the following paragraphs, we briefly summarize the basic mechanism of this approach. SABMs combine continuous time Markov models, random utility models and simulation techniques to analyze network dynamics (Van de Bunt and Groenewegen, 2007). First, the models assume that network changes are time-continuous and decompose changes into unobserved ministeps, in each of which an actor creates a new tie, terminates an existing tie, or does nothing at all (Fischer et al., 2012), even though network changes are only observed at two or more discrete moments in time. The process is conceptualized as a Markov process, implying that for any point in time the probability distribution of the future network, given current and past states of the network, is only a function of the current network (Snijders et al., 2010). Second, the models consider the development of a network over time to be the result of the purposeful, utility-maximizing choices of individual actors (KINNE, 2013). Actors weigh the different options for network change by considering the current network structure (network effects), actors' attributes (actor covariates) and properties of pairs of actors (dyadic covariates) as expressed by an objective function (Snijders et al., 2010). Third, very much as in 'conventional' statistical procedures, SABMs are capable of estimating and testing parameters in order to assess the effect of a given mechanism, while controlling for the possible simultaneous operation of other mechanisms (Snijders et al., 2010). This means that the iterative Markov chain is treated as a Monte Carlo algorithm to draw up expected values, which are then confronted 
with the observed values. A method of moments is then adopted to estimate parameters by minimizing the difference between the observed and expected values (Snijders, 2001). Convergence is checked by assessing deviations in the simulated network statistics from their targeted or observed values (Ruth M. Ripley et al., 2013). SABMs can thus test hypotheses as in conventional statistical models by calculating t-statistics from estimated coefficients and standard errors. Note that SABMs do not make any assumptions about whether the first observed network is in a long-term (dynamic) equilibrium and thus do not model the first observed network itself but only use it as the starting point of the simulations (Snijders et al., 2010), so that results should not be interpreted as increases or decreases over time, but simply as nonrandom tendencies through time (Ingold and Fischer, 2014). In other words, quite opposite results would be obtained if one models and makes inferences about the first observed network. For instance, if the first observed network shows a strong transitivity effect, this does not mean that the extent of transitivity effect in the network will increase or sustain in the future. It would be possible that no transitivity exist in the longitudinal SABM approach where the first observed network is not modeled at all.

The so-called objective function is the core of the model, and determines the probabilities of the tie changes made by the actors (Snijders et al., 2010). The dependent variables in the model are the changes in tie variables derived from the $n \times n$ adjacency matrix $x=\left(x_{i j}\right)$, where $n$ is the total number of actors, and $x_{i j}$ is either 1 (i.e., presence of a tie) or 0 (i.e., absence of a tie). The objective function is assumed to be a linear combination of a set of network effects:

$$
f_{i}\left(x^{0}, x, v, w\right)=\sum_{k} \beta_{k} s_{k i}\left(x^{0}, x, v, w\right)
$$

Where, $i$ is the focal actor, $f_{i}$ is the value of the objective function for actor $i$ depending on the current state $x^{0}$, a potential future state $x$ of the network (i.e., structural or endogenous effects), as well as on actor attributes $v$ and dyadic attributes $w$ (i.e. covariates or exogenous effects). The functions $s_{k i}$ define effects that may potentially drive the changes of network from the perspective of actor $i$ and the weights $\beta_{k}$ are the statistical parameters that express dynamic tendencies of network evolution. If $\beta_{k}$ equals 0 , the corresponding effect plays no role in the network dynamics; if $\beta_{k}$ is positive, there will be a higher probability that the network moves towards the direction with a high score on the corresponding network effect $s_{k i}$, and the converse if $\beta_{k}$ is negative (Snijders et al., 2010).

Because we treat the European air transport network as a non-directed network, we chose to implement the actor-based 'unilateral initiative and reciprocal confirmation' model (Snijders, 2011; Van de Bunt and Groenewegen, 2007). In this model, one airport takes the initiative and decides to create a route to another airport based on the expected utility. The other airport then has to confirm this change, equally based on the expected utility. Note that for termination of a link this is not required (Ruth M. Ripley et al., 2013). This is a reflection of reality, as opening a new route requires mutual agreement between two airports, while termination only requires one 
airport to act. In the next section, we outline the different endogenous (structural) and exogenous (actor and dyadic) effects implemented in our model.

\section{Model specification}

We introduce the main effects in the objective function and the implications of the statistical parameters on the context of air transport network. We include four endogenous network effects (i.e., density, number of distances two, betweenness and transitivity triads) ${ }^{4}$ and four exogenous effects (i.e., two actor covariates and two dyadic covariates reflecting the liberalization of air transport in Europe). The selection of the four endogenous network effects is based on the literature studying air transport networks using complex network theory whereby the classic metrics, such as degree distribution, clustering coefficient (i.e., transitivity commonly used in social sciences), length of shortest path and betweenness have been applied to explore the characteristics of air transport networks (Barrat et al., 2004; Boccaletti et al., 2014; Boccaletti et al., 2006; Ducruet and Beauguitte, 2014; Guimera and Amaral, 2004; Liu et al., 2013b; Zanin and Lillo, 2013).

\subsection{Structural effects}

\section{Density effect}

The most basic effect is defined by the density of airport $i$, which captures the tendency of airport $i$ to connect to other airports during the period under investigation. As we are dealing with a nondirected network, in-degree and out-degree effects are combined into an overall degree or density effect.

$$
S_{1 i}(X)=\sum_{j} x_{i j}
$$

A positive value for the density parameter suggests that airports tend to open more routes; a negative value for the density parameter suggests that airports tend to have fewer routes. Snijders et al. (2010) suggest that this effect should be included in all models, and basically serves as a baseline parameter that can be compared with the intercept in a conventional linear regression (Liu et al., 2013c). From a decision-theoretic perspective, this parameter can be regarded as the overall balance between benefits and costs of an actor (Snijders et al., 2010). For instance, a negative parameter could mean that the costs outweigh the benefits, and vice versa.

\section{Transitivity closure effect}

The transitivity triads effect assesses the tendency of two airports $\mathrm{j}$ and $\mathrm{h}$ to become connected if both airports share a common 'partner' (airport i) in the network. It is defined as the number of transitive patterns in i's relations.

\footnotetext{
${ }^{4}$ These four network effects correspond to nonstop route, one-stop route, hubbing and interconnected subgroup consisting of air transport network in practice.
} 


$$
S_{2 i}(X)=\sum_{j<h} x_{i j} x_{i h} x_{j h}
$$

A positive sign suggests that airports connecting to the same 'partner' airport are more likely to initiate a new route compared to other airports that do not have a 'partner' in common. For example, the more airports $\mathrm{A}$ directly connect that also choose to connect to airport $\mathrm{B}$, the more likely airport A will connect to B directly over time. A negative sign indicates that airports connecting to the same airport are less likely to form closed triangles than other airports that do not have a 'partner' in common.

\section{Number of distances two effect}

Number of distances two effect (nbrDist2) takes into account indirect connections between actors, which is defined by the number of actors $j$ to whom $i$ is indirectly related through at least one intermediary node (i.e., at geodesic distance two).

$$
S_{4 i}(X)=\#\left\{x_{i j}=0, \max _{h}\left(x_{i h} x_{h j}\right)>0\right\}
$$

A positive sign for this effect suggests that airports prefer to open indirect routes connecting other airports through an intermediary airport, whereas the negative nbrDist 2 effect indicates that airport $\mathrm{A}$ is more likely to directly connect to airport B, given that airport A's 'neighbor' airport $\mathrm{C}$ directly connected to airport $\mathrm{B}$ (and regardless of any other indirect connection to airport $\mathrm{B}$ ). Note that although both the transitivity closure effect and $n b r D i s t 2$ effect pertain to the formation of triadic relationships, they differ in that the former is dependent on the number of indirect connections, whereas the latter is independent of the number of indirect connections.

\section{Betweenness effect}

The betweenness effect measures the number of pairs of actors $(j, h)$ that are indirectly linked by actor $i$. A positive sign indicates the tendency that airports prefer to be in between disconnected airports and are more likely to function as 'transfer' centers. A negative sign suggests that airports are less likely to be in between disconnected airports over time.

$$
S_{3 i}(X)=\sum_{j, h} x_{h i} x_{i j}\left(1-x_{h j}\right)
$$

\subsection{Actor covariates}

\section{ECAA Enlargement}

Aiming at establishing a single European 'sky' to facilitate better air transport services for consumers, the European Commission initiated a European Common Aviation Area (ECAA). The ECAA grants its members more freedom to set prices, capacity or frequency. The fifteen Member States of the European Union (EU) plus Iceland and Norway were part of the ECAA in 2000, with Switzerland joining in 2002. During the period under investigation, the enlargement of the ECAA coupled with the extension of the EU in two rounds has resulted in significant 
increases in air traffic and the number of routes and carriers (Niemeier et al., 2012). In 2004, eight East European countries (i.e., Poland, Hungary, the Czech Republic, Slovakia and Slovenia and the three Baltic states of Estonia, Latvia and Lithuania) joined the EU, followed by Bulgaria and Romania in 2007. In addition, the successful negotiation with several Balkan countries (i.e., Albania, Bosnia-Herzegovina, Macedonia, Croatia, Serbia, Montenegro and Kosovo) to join the ECAA in 2006 again stimulated the development of the European aviation market. Dobruszkes (2009) found that low-cost carriers (LCCs) in Europe greatly benefited from the extension of the liberalization of the European skies to the new EU Member States, as their seats supply doubled between 2004 and 2008. The number of city-pairs connecting airports in the established member states to the new ones also showed a significant increase (i.e., from 21 in 2004 to 285 in 2008). We include a dummy variable called 'ECAA enlargement' to explicitly control for the contribution of the enlargement of the ECAA to the dynamics of European airport network during this period. This variable is coded as ' 1 ' if an airport is located in countries that were not a part of the EU or the ECAA in 2003, and we expect a positive effect for this parameter.

\section{LCC bases}

It is known that the liberalization of air transport in Europe has led to the dramatic rise of the importance of (a new generation of) low-cost carriers. LCCs are responsible for a large portion of the dramatic increase of intra-European inter-city connectivity, and have above all impacted the connectivity of 'smaller' cities between 1996 and 2004. (Fan, 2006) found that, in 2004, 60\% of the city-pairs exclusively serviced by LCCs were operated out of secondary and tertiary cities, while $51 \%$ did not involve a primary city at all. Dobruszkes (2006) equally found that more than half of the growth of the supply available in terms of seats was directly due to LCC operations between 1995 and 2004, benefiting both the larger, main cities (such as London, Madrid and Milan) and secondary cities whose growth and survival are largely dependent on LCCs. Collectively, these studies reveal that the emergence of LCC bases is likely to be a major driving force in the evolution of the airport network in Europe. We control for this effect by introducing a dummy variable called 'LCC bases'. In general, LCC bases are defined as airports with significant presence of LCCs in terms of seats or flights, combining two lists developed by Dobruszkes (2006) and the Deutsches Zentrum für Luft- und Raumfahrt (DLR) (2011), respectively ${ }^{5}$.

\subsection{Dyadic covariates}

Former ECAA members - Former ECAA members

\footnotetext{
${ }^{5}$ The LCC bases included in this paper are BCN, BFS, BGY, BRS, CGN, CRL, DUB, DUS, EDI, EMA, FCO, GLA, GVA, HHN, KRK, LGW, LPL, LTN, MAD, MAN, MXP, NCE, NYO, ORY, OSL, RIX, STN, STR, SXF, VIE, VLC.
} 
We include two exogenous dyadic covariates in our model. The variable 'Former ECAA members - Former ECAA members' tests the hypothesis that there is a higher propensity to create ties between the former ECAA members.

Former ECAA members - New ECAA members

The variable 'Former ECAA members - New ECAA members' tests the hypothesis that there is a higher propensity to open new routes between the former ECAA members and the new ECAA members as a result of the enlargement of the ECAA and the EU.

\section{Results and discussion}

\subsection{Model tests and goodness-of-fit}

As the data and model structures for actor-based models are complicated even in the simplest cases and estimating these models are time-consuming, stepwise procedures combining forward steps (where model selection starts with a simple model and effects are gradually added to the model) with backward steps (where model selection starts with a complicated model including all effects that are expected to be strong and non-significant effects are then deleted) are used to select model (Snijders et al., 2007). However, forward model selection is technically and practically preferable to backward model selection due to better convergence and faster computation time. Wald and score-type tests are applied to determine whether individual or various effects should be included in the model based on the (joint) significance of parameters (Ruth M. Ripley et al., 2013) ${ }^{6}$. Moreover, we also assess the goodness-of-fit of the model by comparing degree distribution, geodesic distances distribution and the triad census of networks simulated from the estimated model with the observed networks (Liu et al., 2013c; Ruth M. Ripley et al., 2013). A satisfactory fit is achieved when the observed values are within a band which is a $90 \%$ relative frequency region calculated for the simulated values. The p-value (i.e., larger than 0.10) based on a test of Mahalanobis' distance also shows that the simulated networks can well replicate features of the observed data that are not part of the model.

We report the results of five intermediate model specifications: model 1 is the null model only including the density effect; model 2 accounts for endogenous structural effects only; model 3 also considers the effect of ECAA enlargement, while model 4 incorporates the impacts of LCC bases; and finally, model 5 also includes the two dyadic covariates and, therefore establishes a full set of potential endogenous and exogenous effects driving the changes outline of the European air transport between 2003 and 2009. We present the parameter estimates for each of the five models in table 2. Simulation runs implemented in the SIENA program based on the R platform (Ruth M. Ripley et al., 2013) have been repeated 2000 times. As the t-ratios indicating

\footnotetext{
${ }^{6}$ The difference between the Wald test and the score-type test is that the former is based on the parameter estimates and thereby integrates estimating and testing, whereas the latter tests a parameter without estimating it.
} 
the deviation of observed network data from simulated values are less than 0.1 in all five models, our results exhibit good convergence.

The significance of Score-type tests for models 2-5 suggests improvements in model fit, as new network statistics and actor and dyadic covariates are progressively added into the models. Waldtype tests for joint significance also create statistically significant values for models 2-5, meaning that the changes of the air transport network is influenced by the factors introduced in section 5 . The violin plots in figure 2 show that the full model 5 is fitted well as the observed data are within the $90 \%$ band and the p-values are larger than 0.10 .

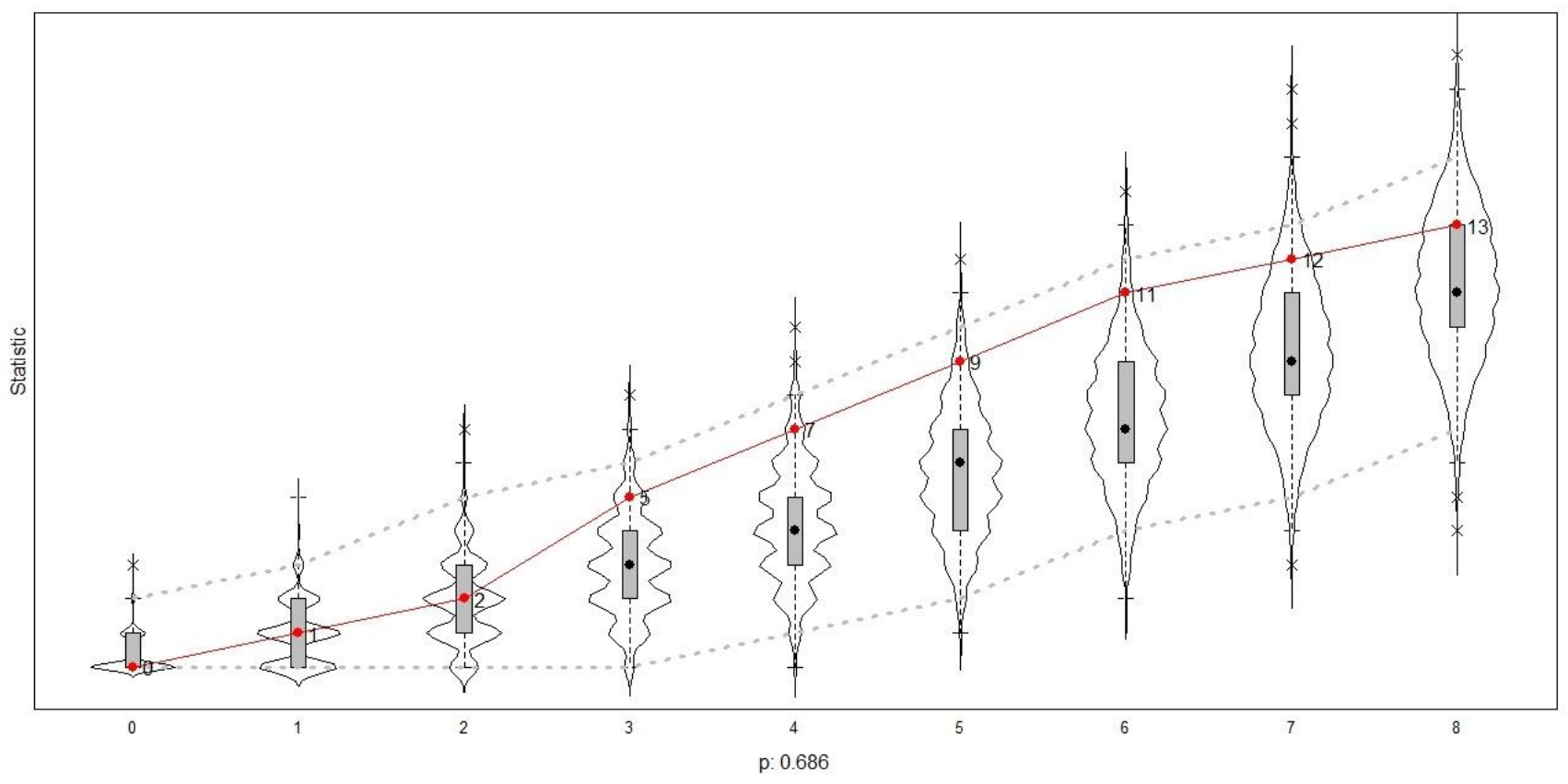

(a) 


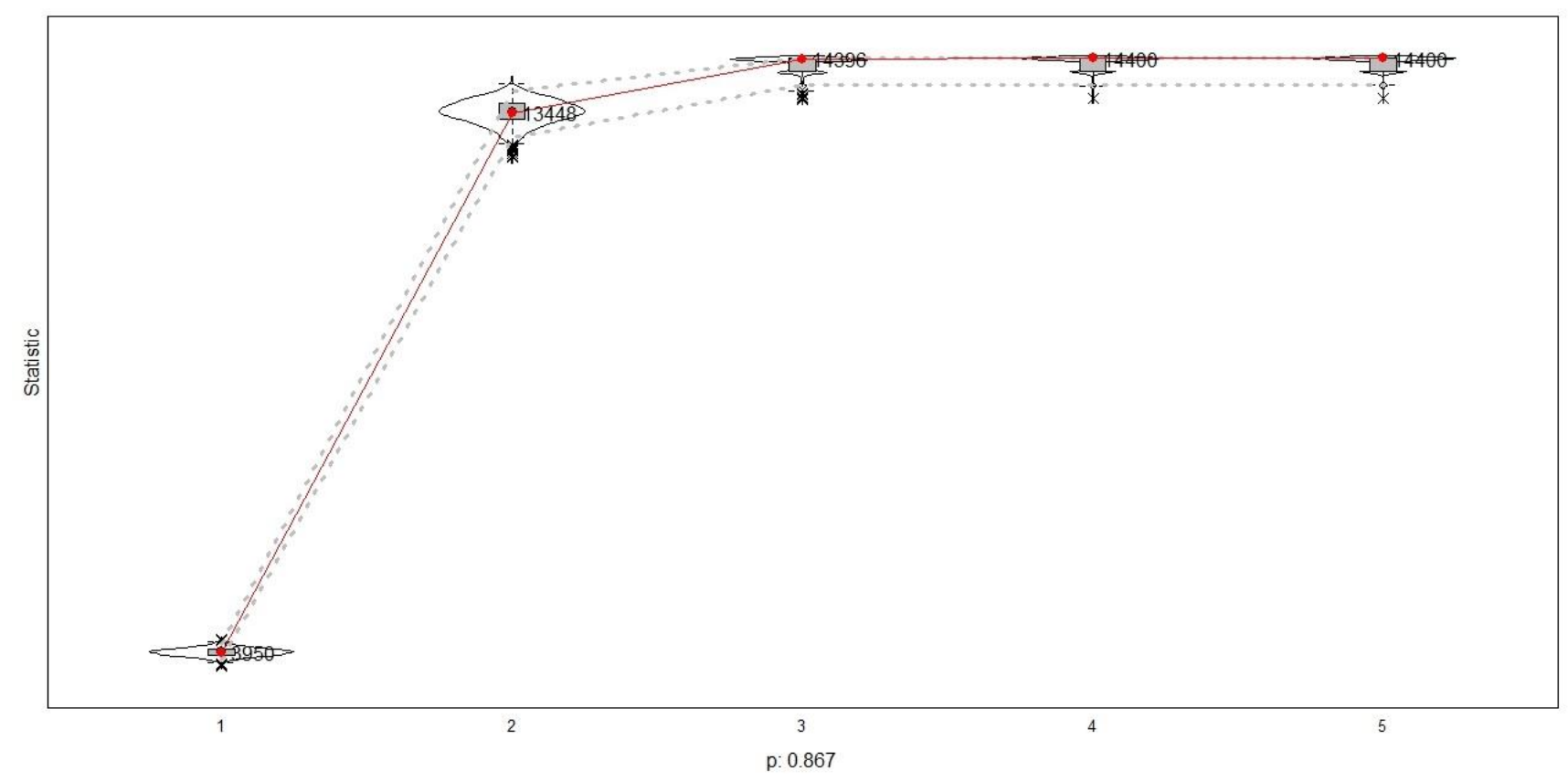

(b)

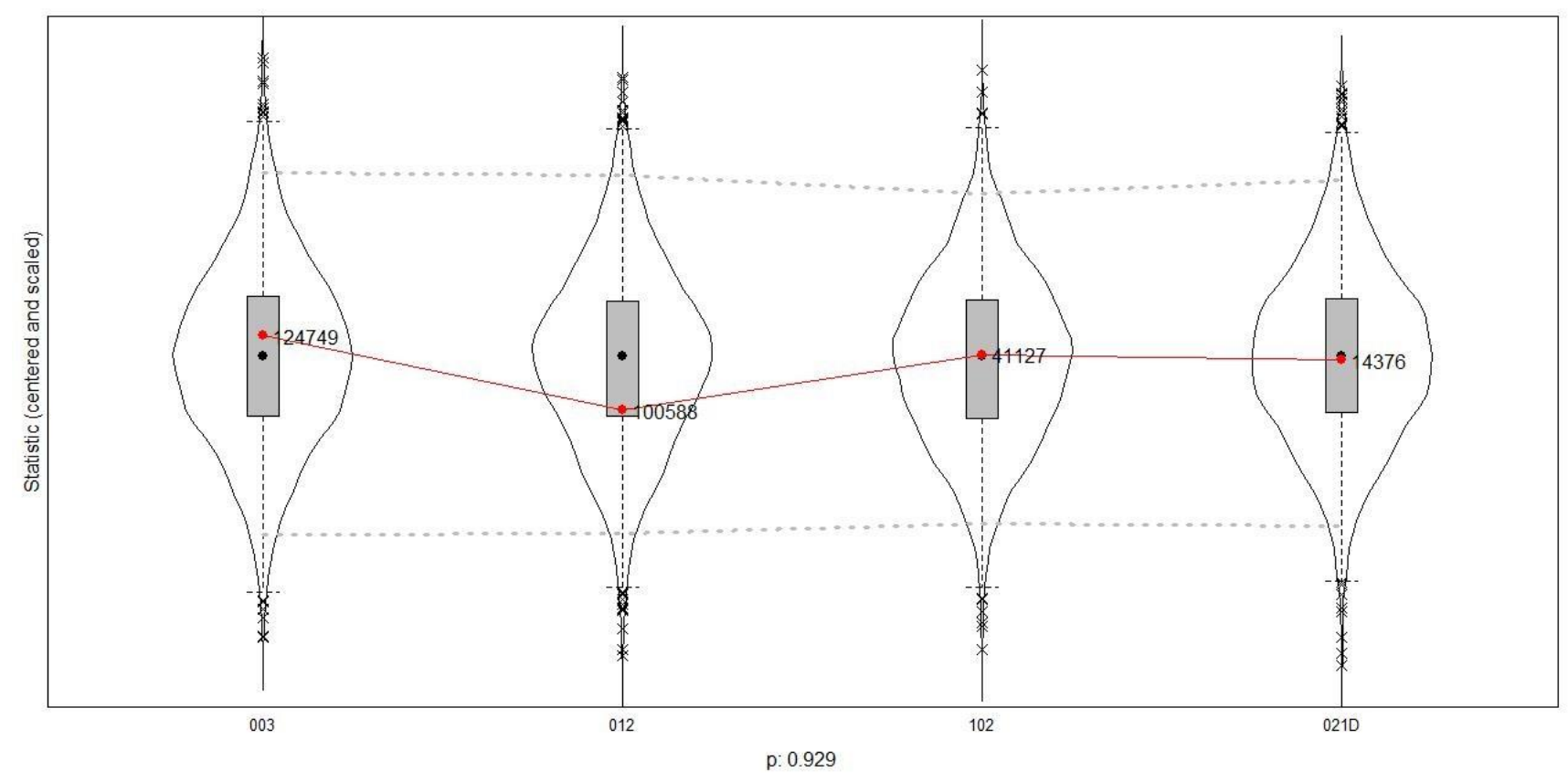

(c)

Fig. 2 Goodness of Fit of Model: (a) Outdegree distribution, (b) Geodesic Distribution, (c) Triad Census 
Note: The goodness of fit of the model is represented by 'violin plots' in which the red solid line shows the observed values and the box plots and 'violins' show the simulated network.

Table 2 Simulation results

\begin{tabular}{|c|c|c|c|c|c|}
\hline & Model 1 & Model 2 & Model 3 & Model 4 & Model 5 \\
\hline Rate parameter & $\begin{array}{l}19.609 * * * \\
(0.845)\end{array}$ & $\begin{array}{l}19.871 * * * \\
(0.852)\end{array}$ & $\begin{array}{l}19.745^{* * *} \\
(0.834)\end{array}$ & $\begin{array}{l}18.648 * * * \\
(0.733)\end{array}$ & $\begin{array}{l}13.476 * * * \\
(0.483)\end{array}$ \\
\hline Density & $\begin{array}{l}-0.706 * * * \\
(0.039)\end{array}$ & $\begin{array}{l}-0.844 * * * \\
(0.090)\end{array}$ & $\begin{array}{l}-0.958 * * * \\
(0.134)\end{array}$ & $\begin{array}{l}-0.710 * * * \\
(0.087)\end{array}$ & $\begin{array}{l}-0.693 * * * \\
(0.110)\end{array}$ \\
\hline Transitive triads & & $\begin{array}{l}0.060 * * * \\
(0.003)\end{array}$ & $\begin{array}{l}0.060 * * * \\
(0.003)\end{array}$ & $\begin{array}{l}0.053 * * * \\
(0.003)\end{array}$ & $\begin{array}{l}0.062 * * * \\
(0.004)\end{array}$ \\
\hline Number of distances two & & $\begin{array}{l}-0.039 * * * \\
(0.009)\end{array}$ & $\begin{array}{l}-0.032 * * * \\
(0.009)\end{array}$ & $\begin{array}{l}-0.046 * * * \\
(0.010)\end{array}$ & $\begin{array}{l}-0.051 * * * \\
(0.014)\end{array}$ \\
\hline Betweenness & & $\begin{array}{l}0.011 * * * \\
(0.005)\end{array}$ & $\begin{array}{l}0.017 * * \\
(0.009)\end{array}$ & $\begin{array}{l}0.006 \\
(0.004)\end{array}$ & $\begin{array}{l}0.010 \\
(0.006)\end{array}$ \\
\hline ECAA Enlargement & & & $\begin{array}{l}0.359 * * * \\
(0.093)\end{array}$ & $\begin{array}{l}0.508 * * * \\
(0.089)\end{array}$ & $\begin{array}{l}0.472 * * * \\
(0.101)\end{array}$ \\
\hline LCC bases & & & & $\begin{array}{l}0.823 * * * \\
(0.075)\end{array}$ & $\begin{array}{l}0.949 * * * \\
(0.091)\end{array}$ \\
\hline $\begin{array}{l}\text { Former ECAA members } \\
-\quad \text { Former } \\
\text { members }\end{array}$ & & & & & $\begin{array}{l}-1.104 * * \\
(0.531)\end{array}$ \\
\hline $\begin{array}{l}\text { Former ECAA members } \\
\text { - New ECAA members }\end{array}$ & & & & & $\begin{array}{l}-0.940 * \\
(0.556)\end{array}$ \\
\hline Tests & & & & & \\
\hline Score-type & & $\begin{array}{l}2181.627 * * \\
* \mathrm{df}=3\end{array}$ & $\begin{array}{l}19.0841 * * \\
* \mathrm{df}=1\end{array}$ & $\begin{array}{l}124.695 * * \\
* \mathrm{df}=1\end{array}$ & $\begin{array}{l}4.9516^{*} \\
\mathrm{df}=2\end{array}$ \\
\hline Wald & & $\begin{array}{l}16.6 * * * \\
\mathrm{df}=3\end{array}$ & $\begin{array}{l}14.9 * * * \\
\mathrm{df}=1\end{array}$ & $\begin{array}{l}119 * * * \\
\mathrm{df}=1\end{array}$ & $\begin{array}{l}4.925^{*} \\
\mathrm{df}=2\end{array}$ \\
\hline
\end{tabular}

Note: Standard errors are within parentheses. $* * * p<0.01, * * p<0.05, * p<0.10$

\subsection{Parameter interpretation}

For the interpretation of the numerical values of the estimated parameters, log odds ratios, which are similar to multinomial logistic regression, can be computed. The estimate for a given covariate is the log odds ratio of the respective probabilities that one actor will choose one particular tie over another, given that the only difference between the two ties is a one-unit change in the covariate of interest (KINNE, 2013; Snijders et al., 2010). Exponentiating the estimates thus yields odds ratios. 
For each model, the rate parameter represents the frequency or the expected average number of opportunities of tie changes by each actor per micro time step. For instance, model 5 suggests that the expected number of changes of network ties for an airport is about 14.

Model 1 is the null model and only includes the basic density effect. The density effect benchmarks the overall tendency for airports to launch new routes. The significant and negative density parameter indicates that airports had a low propensity to make (random) connections to other airports in this period - a probability of $33 \%\left[e^{-0.706} /\left(e^{-0.706}+1\right)\right]$. The density effect is significant and negative in all five models.

Conditional on the density effect in model 1 , model 2 includes three other endogenous network parameters (i.e., three triadic closure effects: transitive triplets, number of actors at distance two and betweenness). The positive transitive triplets effect postulates that more intermediaries will add proportionately to the tendency to transitive closure (Snijders et al., 2010). Numerically, if a potential route ij closes one more triad than an alternative route, then, ceteris paribus, the odds of the route ij being created is greater by a factor of $1.062\left(e^{0.060}\right)$, or about $6.2 \%$. European airports tend to form cohesive and interconnected triadic subgroups for several reasons. First, hub airports have the tendency to form "trunk traffic triplet" to lower costs on inter-hub routes (O'Kelly, 1998; O'Kelly, 2014; O'Kelly et al., 2014). Second, connecting with other hub airports can also improve the accessibility to the rest of their network. In particular, if the dominant carriers of those hubs have incentives to join in strategic alliances, then the inter-hub routes can benefit from higher frequencies and better coordination of time schedules (Doganis, 2006; Zhang et al., 2014). For instance, the strategic integration of the major Austrian and Swiss airports into the 'sub-group' led by Frankfurt airport may contribute to the network closure (Malighetti et al., 2009). In addition, some small airports tend to connect to each other via point-to-point low-cost services, leading to a larger percentage of formation of closed triplets (Malighetti et al., 2009; Redondi et al., 2013).

Number of distances two effect takes into account indirect connections between airports. The significant and negative sign of this effect further confirms the tendency toward network closure. All other effects being equal, if airport A has one more one-stop route, the probability for airport A to open an additional direct route in the future is $49 \%\left[e^{-0.039} /\left(e^{-0.039}+1\right)\right]$. This indicates that keeping connected with the other airports, even through a one-stop route is important for airport managers to increase their airports' connectivity, especially for small airports located in remote areas. For instance, Burghouwt (2007) found that a substantial number of small airports that lost direct air service was partially compensated by an increase in the number of one-stop connections through other airline hubs and traffic nodes.

The significant and positive betweenness parameter suggests that airports have a tendency to occupy 'broker' positions in the network, allowing them to connect two airports that are not directly linked. If airport $\mathrm{A}$ has one more pair of airports that are indirectly linked by it than airport B, then ceteris paribus, the odds that airport A opening a new route is higher than airport 
B by a factor of $1.011\left(e^{0.011}\right)$, or slightly by $1.1 \%$. This corresponds to the practice of 'hub-andspoke' network configuration by full-service carriers in Europe ${ }^{7}$. Moreover, airports with low domestic air-services, such as a number of airports located in the Czech Republic, Slovakia, Hungary, Switzerland, Lithuania and Belgium, often function as the intermediary points to connect airports of Central and Eastern Europe to Western Europe, represented by Brussels and Geneva airport (Malighetti et al., 2009).

Model 3 adds the first nodal covariate "ECAA Enlargement" into model 2 and the result confirms our expectation that the enlargement of the ECAA has benefited the new joint members to open more new air routes. All other effects being equal, being the member of the ECAA increases the odds to open a new route by $43.2 \%\left[\left(e^{0.359}-1\right) * 100 \%\right]$. The significance and sign of structural effects in model 2 remains the same.

Model 4 incorporates the second nodal covariate "LCC bases," and the result shows that the major LCC airports have tended to add a large number of new routes into their networks, overall significantly driving the changing structure of the European air transport network. For instance, being a LCC-airport has a higher probability by $69.5 \%\left[e^{0.823} /\left(e^{0.823}+1\right)\right]$ to open a new route. The significance and sign of parameters in model 3 remains the same, except that the betweenness effect becomes insignificant. This can be explained by the fact that the impact of the major LCC airports on changes of European airport network is so dramatic that the effect of some airports playing bridging roles on network dynamics can be neglected. In addition, the major LCC airports were affected less than the hub airports given the recent economic crisis (Dobruszkes and Van Hamme, 2011), which may make the latter taking more conservative strategy to expand their networks.

Model 5 incorporates the two dyadic covariates into the model. The negative effects of those two dyadic covariates may largely due to the recent economic crisis and they only show marginally significant effects (i.e., the p-values are 0.04 and 0.09, respectively). Dobruszkes and Van Hamme (2011) found that most airports in Europe faced a stagnation or decline in air supply in terms of number of seats during the recent economic crisis corresponding to the decrease of demand. Opening a new route seems to be risky and difficult for airlines to adapt to the economic decline due to long negotiation time and high costs. All the other parameters for endogenous network effects and the two exogenous actor covariates maintain their significance and sign as in model 4.

\subsection{Discussion}

\footnotetext{
${ }^{7}$ It should be noted that betweenness used to define 'hubs' here only shows their spatial characteristics, but not the temporal properties (e.g., the adoption of the wave-system structures to coordinate inbound and outbound flights (Burghouwt and de Wit, 2005; O’Kelly, 2010)).
} 
This section discusses how the results obtained from SABM can benefit airport operators, carriers and local governments. First, we design a toy network to illustrate how the coefficients in table 3 can be applied in practice (Fig. 3).

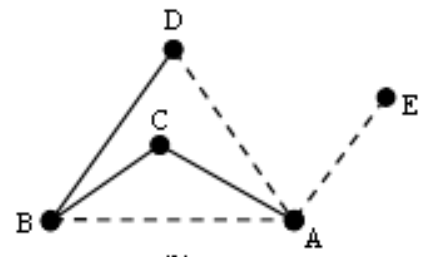

(1)

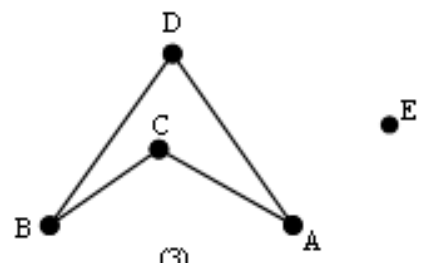

(3)

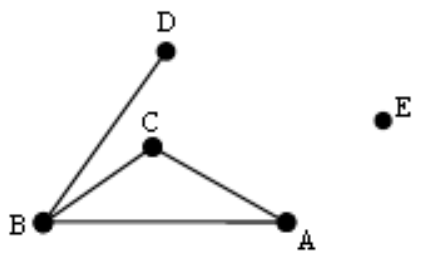

(2)

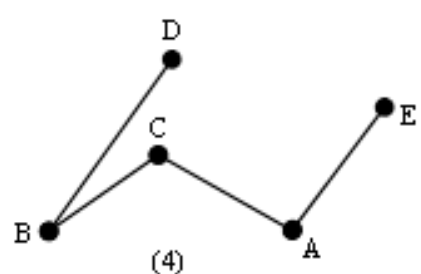

Figure 3 Toy network

Given the estimated coefficients, the objective function for opening a new route is ${ }^{8}$ :

$$
f_{i}(x)=\sum_{j, h}\left(-0.693 x_{i j}+0.062 x_{i j} x_{i h} x_{j h}-0.051 \max _{h}\left(x_{i h} x_{h j}\right)+0.01 x_{h i} x_{i j}\left(1-x_{h j}\right)\right)
$$

Taking airport A as an example, Fig. 3(1) shows its initial network state. If airport A plans to enlarge its network and opens only one new route with three alternatives among airport B, D and $\mathrm{E}$, then the objective function above can be used to calculate and compare the cost of opening a new route for these three cases shown in Fig. 3 (2)-(4). For instance, the cost of connecting to airport $\mathrm{B}$ is: $-0.693 * 2+0.062 * 1-0.051 * 1+0.01 * 0=-1.375$. Table 3 presents the number of network structures and cost for each case and suggests that airport A would choose to connect to B (given that B also 'agrees') due to less costs. This means that airport A tends to deploy a more cohesive network strategy as forming interconnected subgroup may reduce costs.

Table 3 Costs to airport A when considering a new route

\begin{tabular}{cccccc}
\hline \multirow{2}{*}{ Case } & \multicolumn{4}{c}{ Number of Network Structures } & \multirow{2}{*}{ Cost } \\
\cline { 2 - 5 } & Degree & $\begin{array}{c}\text { Transitivity } \\
\text { Triads }\end{array}$ & NbrDist2 & Betweenness & \\
\hline $\begin{array}{c}\text { Initial network state for airport } \\
\text { A (1) }\end{array}$ & 1 & 0 & 1 & 0 & -0.744 \\
Connect to airport B (2) & 2 & 1 & 1 & 0 & -1.375
\end{tabular}

${ }^{8}$ For simplicity, we assume that airport A neither locates in a country being a new ECAA member nor a LCC base. In this way, the objective function only includes the four network effects. 
Taken together, stakeholders such as airport operators, local governments and carriers can use the proposed model to assist in shaping network strategies. For airport operators, they can decide which airport to connect in the future by comparing the costs or utilities of different network 'states' given their existing networks. As the model allows adding exogenous actor and/or dyadic covariates, local governments can make corresponding policies based on the current results. For instance, the probability of opening a route between a former ECAA member and a new ECAA member is very low (i.e., $28 \%$ and the parameter is only marginally significant). Local governments and ECAA committees may thus consider devising more liberalized policies to encourage new entries. In addition, carriers can decide whether to take a conservative network expansion strategy or aggressive network expansion strategy based on the overall change of the air transport network. For instance, this paper finds that airports had a low propensity to make new connections and the air transport network in Europe tend to be more cohesive and interconnected. This implies that it may be costly to open new routes. Therefore, carriers with high cost structure may consider taking a conservative network expansion strategy, but focusing on improving the efficiency of the current network.

\section{Conclusion}

To date, there has been little explicit research on the mechanisms driving the evolution of air transport networks. This paper has attempted to contribute to this under-researched topic by examining how stochastic actor-based modeling, a methodology drawn from the field of longitudinal social network analysis, may contribute to this stream of research. Compared to simpler forms of network analysis, SABM has four distinct advantages. First, simply measuring and comparing number of routes, density, betweenness and other network indicators at two different points in time can only show that the airport network increases or decreases in terms of these measures. However, it cannot verify whether these indicators significantly drive the changes (i.e., adding or deleting a route) of a specific network. Second, simple network analysis cannot control the influence of other factors on the network changes (i.e., the so-called "all other things being equal" effect in statistics). Third, the SABM can not only find out which factors affect network changes, but also quantify to what extent they change. Odds or binary probability can be used to interpret the results. And fourth and finally, the objective function of SABM based on the estimated parameters can help airports choose which airport to connect in the future by comparing the cost or utility of different network 'states'.

The empirical specifics of this study were drawn from data on changes in the European air transport market (for passengers) between 2003 and 2009. Drawing on the SABM framework, we considered four endogenous structural effects (i.e., outdegree, transitive triads, number of distances two and betweenness), two exogenous actor covariates (i.e., the ECAA enlargement and 
LCC bases), as well as two dyadic covariates regarding the opening of new air services between former and new ECAA members.

During this period, airports in Europe showed a low tendency to open new connections. As indicated by the positive transitive triads effect and the negative number of distances two effect, the European airport network has a tendency toward network closure, implying the formation of several cohesive and interconnected triadic subgroups. This corroborates the finding of Malighetti et al. (2009) that subsystems (or modules) of high interconnectivity exist within the European airport network. In addition, the slightly positive betweenness effect means that airports in Europe tend to 'stand' between two indirectly connected airports, corresponding to the development of 'hubs' in the 'hub-and-spoke' network configuration by full-service carriers in Europe, even though this effect is offset when controlling for the impact of growing LCC bases. The positive transitive triplets effect representing network closure and cohesiveness and the positive betweenness effect representing the opposite network concentration and sparseness provide explicit evidence that a multi-layered network in which hub-and-spoke network structure and point-to-point network structure are melted together (Dennis, 2005; Goedeking, 2010), suggesting that the trade-off game between these two types of network structures seems to continue in the future.

Moreover, the enlargement of the ECAA plays a crucial role in driving the changes of airport network in Europe and has benefited the new members to open more new air routes. The major LCC airports also significantly contribute to the changes in the European air transport network. Finally, the recent economic crisis starting from 2007 may hinder European carriers' strategies to expand services between the former ECAA members and the new ECAA members or within each group.

Although we uncover the determinants of evolution of airport network in the pattern of statistical analysis rather than the descriptive level analysis in the previous literature, our model can be improved in the following aspects. First, more observation time points need to be collected between 2003 and 2009. For instance, we could collect data in 2005 to investigate the potential different impacts of EU enlargement or in 2007 to establish separate models for 2003 - 2007 and 2007 - 2009 to control for the influences on network changes before and after the current economic crisis. When handling data with three or more time periods, the issue whether parameters are constant across the periods should be considered. For instance, if the development of average degree does not follow a smooth curve, time-varying variables should be included or separate models should be established to capture time heterogeneity in model parameters (Snijders et al. 2010). In this way, the two dyadic covariates may reveal different results. Second, as stochastic actor-based models for non-directed networks become more and more capable of incorporating interaction terms, we could test whether the network closure is a result of inter-hub connection due to the alliance formation or the adoption of point-to-point network structure of LCCs. Third, more control variables, such as the market power of airports, could also be included to create a more profound model. Finally, SABM is currently limited to binary network 
ties, so data consisting of valued ties (e.g., a continuous measure of strength of ties) had to be dichotomized for using this method. Although choosing an arbitrary cutoff value for dichotomization may affect results in general, our dataset consisting of the actual booking information of origin and destination guarantees the 'real' presence or absence of the ties.

\section{References}

Albers, S., Koch, B., Ruff, C., 2005. Strategic alliances between airlines and airports-theoretical assessment and practical evidence. Journal of Air Transport Management 11, 49-58.

Andrew, S.A., 2009. Regional Integration Through Contracting Networks An Empirical Analysis of Institutional Collection Action Framework. Urban Affairs Review 44, 378-402.

Barrat, A., Barthelemy, M., Pastor-Satorras, R., Vespignani, A., 2004. The architecture of complex weighted networks. Proceedings of the National Academy of Sciences of the United States of America 101, 3747-3752.

Boccaletti, S., Bianconi, G., Criado, R., Del Genio, C., Gómez-Gardeñes, J., Romance, M., Sendiña-Nadal, I., Wang, Z., Zanin, M., 2014. The structure and dynamics of multilayer networks. Physics Reports.

Boccaletti, S., Latora, V., Moreno, Y., Chavez, M., Hwang, D.-U., 2006. Complex networks: Structure and dynamics. Physics reports 424, 175-308.

Buchmann, T., Pyka, A., 2013. The evolution of innovation networks: The case of a German automotive network. FZID Discussion Papers.

Burghouwt, G., 2007. Airline network development in Europe and its implications for airport planning. Ashgate Publishing Limited, Hampshire.

Burghouwt, G., de Wit, J., 2005. Temporal configurations of European airline networks. Journal of Air Transport Management 11, 185-198.

Burghouwt, G., Hakfoort, J., 2001. The evolution of the European aviation network, 1990-1998. Journal of Air Transport Management 7, 311-318.

Cheadle, J.E., Stevens, M., Williams, D., Goosby, B.J., 2013. The Differential Contributions of Teen Drinking Homophily to New and Existing Friendships: An Empirical Assessment of Assortative and Proximity Selection Mechanisms. Social Science Research.

De Neufville, R., 2004. The Future of Secondary Airports: Nodes of a parallel air transport network? Working http://ardent.mit.edu/airports/ASP papers/Cahiers\%20S\%20du\%20Transport\%20English\%2005--

\%20Neufville.pdf.

Dennis, N., 2005. Industry consolidation and future airline network structures in Europe. Journal of Air Transport Management 11, 175-183.

Deutsches Zentrum für Luft- und Raumfahrt (DLR), 2011. Low Cost Monitor 1/2011.

Dobruszkes, F., 2006. An analysis of European low-cost airlines and their networks. Journal of Transport Geography 14, 249-264.

Dobruszkes, F., 2009. New Europe, new low-cost air services. Journal of Transport Geography 17, 423432.

Dobruszkes, F., Van Hamme, G., 2011. The impact of the current economic crisis on the geography of air traffic volumes: an empirical analysis. Journal of Transport Geography 19, 1387-1398.

Doganis, R., 2006. The Airline Business. Routledge, London.

Ducruet, C., Beauguitte, L., 2014. Spatial Science and Network Science: Review and Outcomes of a Complex Relationship. Networks and Spatial Economics 14, 297-316.

EUROCONTROL, 2013. Challenges of Growth 2013: Task 4: European Air Traffic in 2035. 
Fan, T., 2006. Improvements in intra-European inter-city flight connectivity: 1996-2004. Journal of Transport Geography 14, 273-286.

Fischer, M., Ingold, K., Sciarini, P., Varone, F., 2012. Impacts of market liberalization on regulatory network: a longitudinal analysis of the Swiss telecommunications sector. Policy Studies Journal 40, 435457.

Forsyth, P., 2010. Competition Between Major and Secondary Airports: Implications for Pricing, Regulation and Welfare, In: Peter Forsyth, D.G. (Ed.), Airport Competition: The European Experience. Ashgate, pp. 77-87.

Francis, G., Humphreys, I., Ison, S., 2004. Airports' perspectives on the growth of low-cost airlines and the remodeling of the airport-airline relationship. Tourism Management 25, 507-514.

Goedeking, P., 2010. Networks in Aviation: Strategies and Structures. Springer, Heidelberg.

Guimera, R., Amaral, L.A.N., 2004. Modeling the world-wide airport network. The European Physical Journal B-Condensed Matter and Complex Systems 38, 381-385.

Ingold, K., Fischer, M., 2014. Drivers of collaboration to mitigate climate change: An illustration of Swiss climate policy over 15 years. Global Environmental Change 24, 88-98.

Jarach, D., 2001. The evolution of airport management practices: towards a multi-point, multi-service, marketing-driven firm. Journal of Air Transport Management 7, 119-125.

KINNE, B.J., 2013. Network Dynamics and the Evolution of International Cooperation. American Political Science Review 107, 766-785.

Liu, X., Derudder, B., Garcíad, C.G., 2013a. Exploring the co-evolution of the geographies of air transport aviation and corporate networks. Journal of Transport Geography 30, 26-36.

Liu, X., Derudder, B., Liu, Y., 2013b. Regional geographies of intercity corporate networks: The use of exponential random graph models to assess regional network-formation. Papers in Regional Science, n/a-n/a.

Liu, X., Derudder, B., Liu, Y., Witlox, F., Shen, W., 2013c. A stochastic actor-based modelling of the evolution of an intercity corporate network. Environment and Planning A 45, 947-966.

MacDonald, M., 2011. Annual Analyses of the EU Air Transport Market - 2010.

Malighetti, P., Paleari, S., Redondi, R., 2008. Connectivity of the European airport network: "self-help hubbing" and business implications. Journal of Air Transport Management 14, 53-65.

Malighetti, P., Paleari, S., Redondi, R., 2009. Airport classification and functionality within the European network. Problems and Perspectives in Management 7, 183-196.

Neal, Z., 2012. Structural determinism in the interlocking world city network. Geographical Analysis 44, 162-170.

Niemeier, P.D.H.M., Forsyth, P.P., Müller, P.D.J., Gillen, P.D., 2012. Airport Competition: The European Experience. Ashgate.

O'Connor, K., Fuellhart, K., 2013. Change in air services at second rank cities. Journal of Air Transport Management 28, 26-30.

O'Kelly, M.E., 1998. A geographer's analysis of hub-and-spoke networks. Journal of Transport Geography 6, 171-186.

O'Connor, K., 2003. Global air travel: toward concentration or dispersal? Journal of Transport Geography 11, 83-92.

O’Kelly, M., 2014. Network Hub Structure and Resilience. Networks and Spatial Economics, 1-17.

O'Kelly, M., Luna, H., de Camargo, R., de Miranda, G., Jr., 2014. Hub Location Problems with Price Sensitive Demands. Networks and Spatial Economics, 1-29.

O'Kelly, M.E., 2010. Routing traffic at hub facilities. Networks and Spatial Economics 10, 173-191.

Oum, T.H., Adler, N., Yu, C., 2006. Privatization, corporatization, ownership forms and their effects on the performance of the world's major airports. Journal of Air Transport Management 12, 109-121. 
Pels, E., 2008. Airline network competition: Full-service airlines, low-cost airlines and long-haul markets. Research in transportation economics 24, 68-74.

Redondi, R., Malighetti, P., Paleari, S., 2011. New routes and airport connectivity. Networks and Spatial Economics 11, 713-725.

Redondi, R., Malighetti, P., Paleari, S., 2013. European connectivity: the role played by small airports. Journal of Transport Geography 29, 86-94.

Ruth M. Ripley, Tom A.B. Snijders, Preciado, P., 2013. Manual for RSiena.

Snijders, T., 1995. Methods for longitudinal social network data: Review and Markov process models. New Trends in Probability and statistics 3, 211-227.

Snijders, T.A., 2001. The statistical evaluation of social network dynamics. Sociological methodology 31, 361-395.

Snijders, T.A., 2011. Actor-Based Models for Dynamics of Two-Sided Relations.

Snijders, T.A., Steglich, C.E., Schweinberger, M., 2007. Modeling the co-evolution of networks and behavior. Longitudinal models in the behavioral and related sciences, 41-71.

Snijders, T.A., Van de Bunt, G.G., Steglich, C.E., 2010. Introduction to stochastic actor-based models for network dynamics. Social networks 32, 44-60.

Tretheway, M., Kincaid, I., 2010. Competition Between Airports: Occurrence and Strategy, In: Peter Forsyth, D.G. (Ed.), Airport Competition: The European Experience. Ashgate, pp. 119-136.

Van de Bunt, G.G., Groenewegen, P., 2007. An actor-oriented dynamic network approach the case of interorganizational network evolution. Organizational Research Methods 10, 463-482.

Van De Vijver, E., Derudder, B., Witlox, F., 2014. Exploring causality in trade and air passenger travel relationships: the case of Asia-Pacific, 1980-2010. Journal of Transport Geography 34, 142-150.

Waite, J.K., 2009. The impact of airline bankruptcies on airports. Airport Cooperative Research Program Sponsored by the Federal Aviation Administration, 3-61.

Xie, F., Levinson, D., 2009. Modeling the growth of transportation networks: A comprehensive review. Networks and Spatial Economics 9, 291-307.

Zanin, M., Lillo, F., 2013. Modelling the air transport with complex networks: A short review. The European Physical Journal Special Topics 215, 5-21.

Zhang, S., Derudder, B., Witlox, F., 2013. The impact of hub hierarchy and market competition on airfare pricing in US hub-to-hub markets. Journal of Air Transport Management 32, 65-70.

Zhang, S., Derudder, B., Witlox, F., 2014. The determinants of full-service carriers airfares in European hub-to-hub markets. European Journal of Transport and Infrastructure Research 14, 449-467. 